Original Article

\title{
Comparison of Combined and Herobic Training on ABCG1 Lymphocyte Gene Expression in Middle-Hged Men Undergoing Coronary Artery Bypass Grafting
}

\author{
Rokhsareh Moosavi \\ (PhD)Department of Exercise Physiology, \\ Islamic Azad University, Neyshabur \\ Branch, Neyshabur, Iran \\ Amir Rashidlamir \\ (PhD)Department of Exercise Physiology, \\ Ferdowsi University of Mashhad, \\ Mashhad, Iran \\ Rambod Khajeie \\ (PhD)Department of Exercise Physiology, \\ Islamic Azad University, Neyshabur \\ Branch, Neyshabur, Iran \\ Mahmoud Hejazi ID \\ (PhD)Department of Exercise Physiology, \\ Islamic Azad University, Mashhad Branch, \\ Mashhad, Iran \\ Corresponding author: Dr. Rambod \\ Khajeie \\ Tel:+989379092551 \\ Email: r.khajeie@gmail.com \\ Address: Islamic Azad University, \\ Neyshabur Branch, Neyshabur, Iran \\ Received: 2020/05/05 \\ Revised: 2020/02/01 \\ Accepted: 2020/07/05

\section{(c) (7) (\$)}

This work is licensed under a Creative

Commons Attribution 4.0 License.
ABSTRACT

Background and objectives: Cardiovascular disease is one of the most important causes of mortality worldwide. The present study aimed to compare two different cardiac rehabilitation protocols on ATP-binding cassette sub-family $G$ member 1 (ABCGI) lymphocyte expression and blood lipid profile in middle-aged men undergoing coronary artery bypass grafting.

Methods: Forty five middle-aged men who had previously undergone coronary artery bypass surgery were randomly divided into three groups of control $(\mathcal{C} ; n=15)$, aerobic training $(\mathrm{AT} ; \mathrm{n}=15)$ and combined training $(\mathrm{CT} ; \mathrm{n}=15)$. Blood samples were taken before the first and after the last exercise sessions. After isolation of mononuclear cells using Ficoll and mRNA purification, gene expression changes were examined by real-time PCR. Data were analyzed using one-way ANOVA and Bonferroni post-hoc tests.

Results: Eight weeks of training intervention resulted in a significant increase in ABCG1 expression as well as a significant decrease in plasma levels of LDL, triglyceride and total cholesterol in both training groups. However, there was no significant difference between the AT and CT groups. In addition, high-density lipoprotein was significantly increased in the AT and CT groups.

Conclusion: Both AT and CT can increase plasma LDL and increase ABCG1 expression and HDL concentrations, indicating the positive effects of both interventions on the prevention of atherosclerosis.

Keywords: Coronary Artery Bypass, Circuit-Based Exercise, ABCGl, Exercise.

DOI: $10.29252 / \mathrm{mlj} .15 .2 .28$ 


\section{INTRODUCTION}

Atherosclerosis is a major cause of cardiovascular disease, including myocardial infarction, heart failure and stroke (1). Reverse cholesterol transfer (RCT) is a pathway by which accumulated cholesterol in the vessel walls transfers to the liver for excretion, thereby preventing atherosclerosis. Cholesterol delivery and excretion are regulated by the ATP-binding cassette (ABC) transporters superfamily membrane vectors. The human genome has 48 different $\mathrm{ABC}$ vectors, classified into seven ABCA to ABCG groups. $A B C G 1$ belongs to the $\mathrm{G}$ index of the $\mathrm{ABC}$ transporter family. Animal studies have shown that $A B C G 1$ plays a significant role in cholesterol outflow into high-density lipoprotein (HDL) and RCT. Overexpression of the $A B C G 1$ gene in transgenic mice may have a protective role against lipid accumulation in the liver and lungs $(2,3)$. Research has shown that $A B C G 1$ is highly expressed in endothelial cells. Partial vector plays a remarkable role in removing cholesterol from endothelial cells and protects against endothelial dysfunction as well as promoting cholesterol flow from endothelial cells to HDL and reduces the amount of existing cholesterol (4). Thus, regulation of RCT by $A B C G 1$ indicates its important physiological role. It has been reported that $A B C G 1$ and $A B C A 1$ can synergistically enhance cellular cholesterol efflux in vitro (5). In addition to clinical interventions, it has been shown that physical activity protects against cardiovascular disease through suppression of sympathetic activity, blood pressure and heart rate, increased blood flow and nitric oxide production, vascular clearance, reduction of inflammatory cytokines and formation of reactive oxygen species (6). Regarding cardiovascular diseases, it has been reported that physical activity significantly increases expression of ABCG5 (7), $A B C A 1$ and $A B C G 1$ $(8,9)$. In regard to $C A B G$ patients, studies have shown a significant increase in $A B C G$ gene expression following an aerobic training (AT) program (10). The role of combined training (CT) on ABCG1 gene expression changes in CABG patients has received little attention. The positive effect of physical activity on ABCG1 gene expression and the improvement of RCT provide a basis for their protective role in the process of atherosclerosis. However, studies comparing the two types of AT and CT protocols on $A B C G 1$ lymphocyte gene expression changes in $C A B G$ patients are very limited, and most studies have focused on functional performance of these patients. Thus, the aim of the present study was to compare AT and CT protocols on ABCG1 lymphocyte gene expression and blood lipid profile in middleaged men undergoing coronary artery bypass surgery.

\section{MATERIALS AND METHODS}

This semi-experimental study was performed on middle-aged men (aged 40-60 years) undergoing coronary artery bypass surgery in the Javad Alaemeh Heart Hospital in Mashhad (Iran) in 2018. Blood samples, body measurements and cardiopulmonary fitness were collected before and after the training intervention. The subjects were randomly divided into three groups: AT $(n=15), C T$ $(n=15)$ and control $(n=15)$.

A primary clinical evaluation specialist evaluated the severity and extent of heart disease. Subsequently, individuals who had previously undergone coronary artery bypass surgery who were homogeneous in disease level and physically fit to exercise, entered the study. Inclusion criteria were as follows: systolic and diastolic blood pressure of no more than $160 \mathrm{mmHg}$ and $100 \mathrm{mmHg}$, respectively, cognitive, visual and auditory health, no use of walking aids like canes and walkers, at least two months have passed since their surgery, oxygen uptake of more than five metabolic equivalent of task $(11,12)$ and age of 40 to 60 years. Exclusion criteria were unstable angina, uncomplicated heart failure, myocardial infarction, ventricular erythema, neurologic medication (13). The study received approval from the Human Subject Committee of Islamic Azad University of Neyshabur

(IR.IAU.NEYSHABUR.REC.1397.007).

Participants performed AT exercise three days a week for eight weeks. The exercise included treadmill walking (20 to 30 minutes), pedaling on a fixed bike (10 to 12 minutes) and arm ergometer (eight to ten minutes). Stretching exercises were used for warm up at the beginning of the session and for cool down at the end of the exercise session. Exercises began with moderate intensity. In addition to the amount of fatigue and cardiac symptoms, 
the duration and intensity of exercise were adjusted at $60 \%$ of maximum heart rate. The intensity and duration of exercise gradually increased based on patients' ability to reach $80 \%$ of their maximum heart rate in the last seven to ten sessions (14).

In each session of CT, the patients first performed AT and performed simultaneous resistance training after a short rest as described below.

Resistance training consisted of specified exercises that were performed three sessions a week for eight weeks. The training was performed in two sets with 10 repetitions in the initial sessions and up to 15 repetitions in the next training sessions. Exercise included squat with physio ball, shoulder flexion, shoulder abduction, elbow flexion, hip flexion, hip abduction and plantar flexion and dorsiflexion of ankle.

Due to the ability of the participants, the exercises were initially performed without overload and merely by moving the limbs and gradually with a weak thera-band and finally with very light overloads (15).

The movements were initially performed with seven repetitions using a light yellow thera-band (set as lower intensities). Then, the number of repetitions were gradually increased to 15 repetitions in the subsequent training sessions.

Blood sampling was performed in two stages, 48 hours before the first training session and 48 hours after the last training session, after 12 hours of overnight fasting. Blood samples (10 $\mathrm{ml}$ ) were collected in test tubes with EDTA anticoagulant. After isolation of mononuclear cells by ficoll and centrifugation, mRNA was purified using a commercial kit. Quantitative real-time-PCR method was performed to evaluate the relative expression of the gene (16). Enzymatic method was used to measure lipid profile using Pars Azmoon kit (Tehran, Iran).

The mononuclear cells were embedded in liquid nitrogen, completely crushed, homogenized in RLT buffer and frozen for future use.

The lysate was transferred directly to the QIAshredder and centrifuged at high speed for two minutes. The $200 \mathrm{ng}$ mRNA cDNA was synthesized using the Oligo primer (dT) and a kit (St. Leon-Rot Fermantas GmbH, Germany) according to the manufacturer's instruction.

Real-time PCR was performed to investigate the relative expression of $A B C G 1$ gene (11). The sequence of the primers and beta-actin are shown in table 1.

Table 1- Oligonucleotide sequence of the primers used in the PCR experiment

\begin{tabular}{ccc}
\hline Gene name & Type & Sequences (5 to3) \\
\hline ABCG1 & Forward & CCC AAC TGC AGC CAC TCT G \\
& Reverse & GTG AAG AAA GGC CGC AGA GG \\
& Forward Actin & CCT ATG TTC TCA GCA GCT TC \\
& Reverse & GAA TTT CCT GGC TGT CCC TG \\
\hline
\end{tabular}

After confirming the normality of the data distribution by Shapiro-Wilk test, one-way ANOVA and Bonferroni post hoc test were used to examine intergroup and intragroup differences, respectively. All statistical analyses were performed using SPSS software (version 24) and at significance level of 0.05 .

\section{RESULTS}

Subject's characteristics are presented in table 2. There were significant main effects of time for $A B S C G 1$ expression (Figure 1). There was a significant difference in $A B C G 1$ lymphocyte gene expression between the AT and $\mathrm{C}$ groups $(\mathrm{P}=0.002)$ as well as $\mathrm{CT}$ and $\mathrm{C}$ groups $(\mathrm{P}=0.001)$. However, no significant difference was observed between the AT and $\mathrm{CT}$ groups $(\mathrm{P}>0.05)$. In addition, HDL and LDL levels differed significantly between the $\mathrm{CT}$ and $\mathrm{C}$ groups and between the $\mathrm{C}$ and $\mathrm{CT}$ groups $(\mathrm{P}<0.05)$.

However, there was no significant difference between the AT and CT groups $(\mathrm{P}>0.05)$.

Table 2- Subiect characteristics

\begin{tabular}{cccccc}
\hline Group & Number & Age (year) & Height $(\mathrm{cm})$ & Weight $(\mathrm{kg})$ & $\begin{array}{c}\text { Duration of } \\
\text { disease } \\
\text { (months) }\end{array}$ \\
\hline AT & 15 & $46.9 \pm 3.23$ & $171.1 \pm 3.6$ & $\mathbf{8 0 . 1 4} \pm 9.12$ & $150 \pm 68.19$ \\
CT & 15 & $47.4 \pm 3.23$ & $170.2 \pm 3.5$ & $80.16 \pm 8.99$ & $150 \pm 69.01$ \\
C & 15 & $47.4 \pm 2.75$ & $170.9 \pm 3.9$ & $80.1 \pm 8.8$ & $149 \pm 69.12$ \\
\hline
\end{tabular}


Figure 1- ABCG1, HDL and LDL values in different study groups. * shows significant difference from baseline; \# shows significant difference between groups.
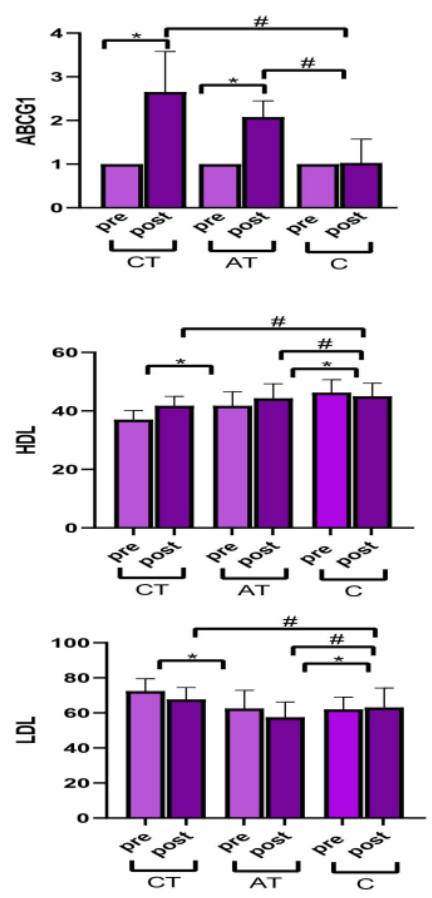

\section{DISCUSSION}

We aimed to compare the effects of AT and CT protocols on $A B C G 1$ expression in lymphocytes and blood lipid profile in middleaged men undergoing coronary artery bypass surgery. The results showed that both AT and $\mathrm{CT}$ increased $A B C G 1$ gene expression in mononuclear cells. Yamamoto et al. (2015) showed that resistance training increased muscle strength, exercise capacity and mobility in middle-aged CAD patients (17). Gambassi et al. (2019) showed that acute response of AT in cardiovascular rehabilitation program after $\mathrm{CABG}$ improved cardiac autonomic control in patients undergoing CABG (18). Although there has been limited evidence about the effects of rehabilitation training programs on CABG patients, there is no significant consensus on the training intensity, duration, and even type of rehabilitation programs. In addition, researchers have sought to assess different training protocols such as AT, resistance training and CT to draw definite conclusions. The main findings of this study showed that $A B C G 1$ increased $108 \%$ in AT group and $165 \%$ in $\mathrm{CT}$ group. In addition, Gaieni indicated that eight weeks of CT is more effective than AT in improving functional capacity (cardiovascular fitness) and muscle strength in CABG patients (19). However, Ghroubi et al. reported that resistance training would result in a greater increase in physical performance compared to AT (16).

Most of the common atherogenic abnormalities in humans appear to be due to damage to the $\mathrm{ABC}$ transporters or suppression of their expression. Diabetes and other metabolic disorders decrease the expression of $\mathrm{ABC}$ transporters via several mechanisms, which increases the risk of cardiovascular disease.

CAD patients are relatively resistant to interventions designed to increase expression of $\mathrm{ABC}$ cholesterol transporters. Thus, mechanisms that impair ABC transducers or affect cellular pathways need to be specifically and directly targeted therapeutically (20).

One of the important components of RCT is the $\mathrm{ABC}$ transporter family genes by liver- $\mathrm{x}$ receptor. These transporters, notably ABCA1 and ABCG1, are key regulators of cholesterol and phospholipid removal from macrophage foam cells (21). However, ABCA1 transduces these substances into lipid-free lipoproteins, causing early HDL formation (22).

In an study by Dashtkhaki Lily et al. on ABCG8 alterations in peripheral blood 
mononuclear cells, eight weeks of water-based and land-based resistance training in middleaged women undergoing $\mathrm{CABG}$ induced similar adaptations regarding increments of ABCG8 expression that may indirectly prevent cholesterol accumulation in the coronary arteries (23). In this regard, Rashidelmir et al. (2012) investigated the influence of AT and RT on ABCG1 gene expression in peripheral blood mononuclear cells in female athletes, illustrating that CT could improve RCT and ABCG1 expression in peripheral blood mononuclear cells (20). Based on the results of the present study, both CT and AT improved cardiovascular function. In a previous study, 12 weeks of regular physical activity significantly increased the expression of ABCG1 in blood cells of sedentary obese women (24). Moreover, Ramezani et al. reported that eight weeks of AT could increase ABCG8 and improve RCT in overweight women (25). It has been also shown that $\mathrm{ABCA} 1$ and $\mathrm{ABCG} 1$ overexpression is associated with increased level of lipoprotein lipase, hepatic lipase, pre-beta HDL and cholesterol acetyltransferase (LCAT), which play important roles in the prevention of cardiovascular disease $(11,20)$.

ABCG1 is required for HDL to exert a protective effect against LDL. Physical activity and positive regulation of peroxisome activator receptors (PPARs) plays an important role in regulating the expression of genes involved in cellular cholesterol transmission and expression of the $\mathrm{ABC}$ transporter family. In addition, PPAR- $\alpha$ activity additionally increases the expression of lipoprotein lipase and apolipoprotein (apo A-I) A-V and simultaneously decreases the expression of 1llc-apo in the liver. This process is known to be one of the inhibitors of atherosclerosis, which increases the expression of liver X receptor. In this regard, it has been reported that CT significantly increases PPAR after six and twelve months (26). In our study, LDL level decreased by $8.69 \%$ in the AT group and by $6.97 \%$ in the CT group. The increase in HDL was more profound in the CT group compared to the AT group (12.92\% vs $6.18 \%)$.

Controlling lipid profile is essential for improving cardiovascular risk factors, which is very important for individuals with $C A D$. Cholesterol concentration can be reduced by taking fat-lowering drugs, which can reduce risk of mortality following cardiovascular disease (27).

Regarding the effect of AT on reducing atherogenic factors, it can be argued that AT is associated with a decrease in body fat and LDL concentration as well as an increase in HDL. However, both environment and liver tissues and affect the increased activity of LCAT enzyme during short-term or long-term physical activity (28). These changes in lipid profile markers may be related to other mechanisms, including changes in lipoprotein lipase concentrations (29). The reduction of cholesterol biosynthesis decreases the intracellular cholesterol content. In hepatocytes, lowering cholesterol reduces the secretion of lipoproteins containing Apo B and increases the activity of LDL receptors, which both reduce blood LDL levels (30). Increasing the expression of the ABCG8 gene can also reduce the production of Apo-B, which is the main precursor to LDL production (31).

\section{CONCLUSION}

Based on the results, CT may result in overexpression of the $A B C G 1$ gene via increasing the function of $\mathrm{RCT}$ in $\mathrm{CABG}$ patients. The results indicate that $\mathrm{CT}$ improves RCT function and expression of lymphocyte ABCG1 and reduces plasma LDL concentrations. A limitation of the present study was failure to accurately control the diet of the participants. However, they were instructed to maintain their previous dietary habits. Based on the results, performing AT as well as CT can improve muscle strength, functional capacity, blood pressure and lipid profile in CABG patients (27).

\section{ACKNOWLEDGMENTS}

The authors would like to express their gratitude to the Rehabilitation Department of Javad Al-A'meh Heart Hospital and the patients who helped us in this study.

\section{CONFLICT OF INTEREST}

The authors declare that there is no conflict of interest regarding publication of this article. 


\section{References}

1. Bagheri R, Darroudi S, Hosseini SM, Nikkar H, Rashidlamir A. Effects of High-Intensity Resistance Training and Aerobic Exercise on Expression of ABCG4, ABCG5 and ABCG8 Genes in Female Athletes. Medical Laboratory Journal. 2020;14(3):40-5. [DOI:10.29252/mlj.14.3.40] [Google Scholar]

2. Out R, Hoekstra M, Hildebrand RB, Kruit JK, Meurs $\mathrm{I}$, Li Z, et al. Macrophage ABCG1 deletion disrupts lipid homeostasis in alveolar macrophages and moderately influences atherosclerotic lesion development in LDL receptor-deficient mice. Arteriosclerosis, thrombosis, and vascular biology. 2006;26(10):2295-300. [DOI:10.1161/01.ATV.0000237629.29842.4c] [Google Scholar]

3. Wang HH, Patel SB, Carey MC, Wang DQH. Quantifying anomalous intestinal sterol uptake, lymphatic transport, and biliary secretion in Abcg8-/mice. Hepatology. 2007;45(4):998-1006. [DOI:10.1002/hep.21579] [PubMed] [Google Scholar]

4. Terasaka N, Westerterp M, Koetsveld J, FernándezHernando C, Yvan-Charvet L, Wang $\mathrm{N}$, et al. ATPbinding cassette transporter $G 1$ and high-density lipoprotein promote endothelial NO synthesis through a decrease in the interaction of caveolin-1 and endothelial NO synthase. Arteriosclerosis, thrombosis, and vascular biology. 2010;30(11):2219-25. [DOI:10.1161/ATVBAHA.110.213215] [PubMed] [Google Scholar]

5. Gelissen IC, Harris M, Rye K-A, Quinn C, Brown AJ, Kockx M, et al. $A B C A 1$ and $A B C G 1$ synergize to mediate cholesterol export to apoA-I. Arteriosclerosis, thrombosis, and vascular biology. 2006;26(3):534-40. [DOI:10.1161/01.ATV.0000200082.58536.e1]

[PubMed] [Google Scholar]

6. Tian D, Meng J. Exercise for prevention and relief of cardiovascular disease: prognoses, mechanisms, and approaches. Oxidative Medicine and Cellular Longevity. 2019;2019. [DOI:10.1155/2019/3756750] [PubMed] [Google Scholar]

7. KHAJEI R, HAGHIGHI AH, HAMEDINIA MR, RASHID LA. Effects of Eight Week Aerobic Training on Monocytes ABCG5 Gene Expression in Middle-Aged Men after Heart Bypass Surgery. 2017. [Google Scholar]

8. HOSSEINI SM, DARRUDI S, TALEBI K, RASHIDLAMIR A. EFFECT OF RESISTANCE AND AEROBIC TRAINING ON ABCA1, ABCGI GENE EXPRESSION, HDL-C AND LDL-C LIPOPROTEIN LEVELS FEMALE ATHLETES. 2017. [Google Scholar]

9. Haj Ghasemi Alireza RAA, Kurdi Mohammad Reza, Rashid lamir Amir, Gharghi Akhtar. Investigating the effect of cardiac rehabilitation exercise on the expression of abcal gene in PBMN cells of patients with cardiac ischemia. Journal of Knowledge and Health. 2016. [Google Scholar]
10. Rashidlamir A, Dastani M, Saadatnia A, Bassami MR. Effect of Cardiac Rehabilitation Training on ABCA1 Expression in Lymphocytes of Patients Undergoing Coronary Artery Bypass Graft Operation. Zahedan Journal of Research in Medical Sciences. 2018;20(6). [DOI:10.5812/zjrms.11277] [Google Scholar]

11. Ghanbari-Niaki A, Rahmati-Ahmadabad S, ZareKookandeh N. ABCG8 gene responses to 8 weeks treadmill running with or without Pistachia atlantica (Baneh) extraction in female rats. International journal of endocrinology and metabolism. 2012;10(4):604. [DOI:10.5812/ijem.5305] [PubMed] [Google Scholar]

12. Arthur HM, Gunn E, Thorpe KE, Ginis KM, Mataseje L, McCartney $\mathrm{N}$, et al. Effect of aerobic vs combined aerobic-strength training on 1-year, postcardiac rehabilitation outcomes in women after a cardiac event. Journal of rehabilitation medicine. 2008;39(9):730-5. [DOI:10.2340/16501977-0122] [PubMed] [Google Scholar]

13. Gayda M, Brun C, Juneau M, Levesque S, Nigam A. Long-term cardiac rehabilitation and exercise training programs improve metabolic parameters in metabolic syndrome patients with and without coronary heart disease. Nutrition, Metabolism and Cardiovascular Diseases. 2008;18(2):142-51.

[DOI:10.1016/j.numecd.2006.07.003] [PubMed] [Google Scholar]

14. KHAJEI R, HAGHIGHI AH, HAMEDINIYA M, RASHID LA. THE EFFECT OF EIGHT WEEKS AEROBIC EXERCISE ON THE EXPRESSION OF LIVER MONOCYTE X-RECEPTOR GENE VALUE AND LIPID PROFILE OF MIDDLE-AGED MEN AFTER CARDIAC ARTERY BYPASS GRAFT SURGERY. 2018. [Google Scholar]

15. Pollock ML, Franklin BA, Balady GJ, Chaitman BL, Fleg JL, Fletcher $\mathrm{B}$, et al. Resistance exercise in individuals with and without cardiovascular disease: benefits, rationale, safety, and prescription an advisory from the committee on exercise, rehabilitation, and prevention, council on clinical cardiology, American Heart Association. Circulation. 2000;101(7):828-33. [DOI:10.1161/01.CIR.101.7.828] [PubMed] [Google Scholar]

16. Ghroubi S, Elleuch W, Abid L, Abdenadher M, Kammoun S, Elleuch M. Effects of a low-intensity dynamic-resistance training protocol using an isokinetic dynamometer on muscular strength and aerobic capacity after coronary artery bypass grafting. Annals of physical and rehabilitation medicine. 2013;56(2):85-101. [DOI:10.1016/j.rehab.2012.10.006] [PubMed] [Google Scholar]

17. Yamamoto S, Hotta K, Ota E, Mori R, Matsunaga A. Effects of resistance training on muscle strength, exercise capacity, and mobility in middle-aged and elderly patients with coronary artery disease: a metaanalysis. Journal of Cardiology. 2016;68(2):125-34. [DOI:10.1016/j.jjcc.2015.09.005] [PubMed] [Google Scholar] 
18. Gambassi BB, Almeida FdJF, Almeida AEAF, Ribeiro DAF, Gomes RSA, Chaves LFC, et al. Acute Response to Aerobic Exercise on Autonomic Cardiac Control of Patients in Phase III of a Cardiovascular Rehabilitation Program Following Coronary Artery Bypass Grafting. Brazilian journal of cardiovascular surgery. 2019;34(3):305-10. [DOI:10.21470/16789741-2019-0030] [PubMed] [Google Scholar]

19. Gaieni A. COMPARISON OF EIGHT WEEKS OF COMBINED AND AEROBIC TRAINING ON FUNCTIONAL CAPACITY, BODY COMPOSITION AND STRENGTH IN POST-CORONARY ARTERY BYPASS GRAFT CARDIAC PATIENTS. 2013. [Google Scholar]

20. Rashidlamir A. Investigation of the effect of aerobic and resistance exercises on peripheral blood mononuclear cells ABCG1 gene expression in female athletes. SSU_Journals. 2012;20(1):1-9. [Google Scholar]

21. Li AC, Binder CJ, Gutierrez A, Brown KK, Plotkin $\mathrm{CR}$, Pattison JW, et al. Differential inhibition of macrophage foam-cell formation and atherosclerosis in mice by PPAR $\alpha, \beta / \delta$, and $\gamma$. The Journal of clinical investigation. 2004;114(11):1564-76. [DOI:10.1172/JCI18730] [PubMed] [Google Scholar]

22. Butcher LR, Thomas A, Backx K, Roberts A, Webb $\mathrm{R}$, Morris K. Low-intensity exercise exerts beneficial effects on plasma lipids via PPAR . Medicine \& Science in Sports \& Exercise. 2008;40(7):1263-70. [DOI:10.1249/MSS.0b013e31816c091d] [PubMed] [Google Scholar]

23. Dashtkhaki Lily Ziauddin RlA, Naqibi Saeed. Changes in ABCG8 gene expression in PBMN cells following eight weeks of water resistance and drought resistance in middle-aged women after coronary artery bypass graft surgery. Journal of Sabzevar University of Medical Sciences. 2017;25.

24. TOFIQHY A. TWELVE WEEKS OF AEROBIC TRAINING EFFECT ON GENE EXPRESSION IN OBESE SEDENTARY WOMEN ABCG1. 2013.

25. Ramezani Z, Hejazi SM, Rashidlamir A. The Effect of Eight Weeks Aerobic Exercise on the Atherogenic Ratio and ABCG8 Gene Expression in PBMC Globules of Overweight Women. Iranian Journal of Diabetes and Obesity. 2017;9(3):95-100. [Google Scholar]
26. Fatone C, Guescini M, Balducci S, Battistoni S, Settequattrini A, Pippi R, et al. Two weekly sessions of combined aerobic and resistance exercise are sufficient to provide beneficial effects in subjects with Type 2 diabetes mellitus and metabolic syndrome. Journal of endocrinological investigation. 2010;33(7):489-95. [DOI:10.1007/BF03346630] [PubMed] [Google Scholar]

27. Afzal Aghaei Ehsan HMR, Attarbashi Moghadam Behrooz, Tavakol Kamran, Zandparsa Amir Farhang, Jalaei Shohreh, Abdollahi Alireza, Mousavi Shiva. Investigating the effect of cardiac rehabilitation on changes in blood lipid profile of Iranian men and women with coronary artery disease referred to the cardiac rehabilitation department of Imam Khomeini Hospital. New rehabilitation. 2010;4:45-9. [Google Scholar]

28. Ghanbari Niaki Abbas FR, Ramroodi Soghra.. Effect of 8 weeks of endurance training with different periods on total HDL, HDL2 and HDL3 plasma rest levels in male rats. Sports and move Biological Sciences. 2011;10:27-36

29. Tambalis K, Panagiotakos DB, Kavouras SA, Sidossis LS. Responses of blood lipids to aerobic, resistance, and combined aerobic with resistance exercise training: a systematic review of current evidence. Angiology. 2009;60(5):614-32. [DOI:10.1177/0003319708324927] [PubMed] [Google Scholar]

30. Kajinami K, Brousseau ME, Nartsupha C, Ordovas JM, Schaefer EJ. ATP binding cassette transporter G5 and G8 genotypes and plasma lipoprotein levels before and after treatment with atorvastatin. Journal of lipid research. 2004:45(4):653-6. [DOI:10.1194/jlr.M300278-JLR200] [PubMed] [Google Scholar]

31. Chan D, Watts G, Barrett P, Whitfield A, Van Bockxmeer F. ATP-binding cassette transporter G8 gene as a determinant of apolipoprotein B-100 kinetics in overweight men. Arteriosclerosis, thrombosis, and vascular biology. 2004;24(11):2188-91. [DOI:10.1161/01.ATV.0000143532.93729.d6] [PubMed] [Google Scholar]

How to Cite:

Moosavi R, Rashidlamir A, Khajeie R, Hejazi M[Comparison of Combined and Aerobic Training on ABCG1 Lymphocyte Gene Expression in Middle-Aged Men Undergoing Coronary Artery Bypass Grafting]. mljgoums. 2021; 15(2): 28-34 DOI: $10.29252 / \mathrm{mlj} .15 .2 .28$

(C) The authors 